\section{A New Steerable Catheter for Improving the Efficiency of Fluoroscopy-Guided Laser Lithotripsy}

Since the first report of successful laser-induced shock-wave lithotripsy of bile duct stones (1) various laser systems have been developed and used for bile duct lithotripsy (2). Perhaps the most important step forward was the development of a stone-tissue discrimination system (STDS), which appears to be effective in reducing the risk of tissue damage caused by misapplied laser pulses. The system allows the laser to be used under purely radiological control in many patients $(3,4)$. Previous reports by different groups $(3,4)$ using the STDS laser system have described the following problems encountered in reaching the stone under pure fluoroscopic guidance; a) when it is located behind a stenosis; b) in a tortuous common duct; c) in the intrahepatic bile ducts; and d) when it is located near the hepatic hilum. Various authors have therefore described the need for a steerable catheter to facilitate placement of the glass fiber on the surface of the stone (2-4).

We report here the development of a prototype for this type of steerable catheter, which seems to solve or reduce these problems. The prototype has been developed in cooperation with Polydiagnost Ltd. (Pfaffenhofen, Germany). The catheter has an outer diameter of $7 \mathrm{Fr}$ and a metal tip for radiological control. It consists of two working channels: one with a diameter of $1.0 \mathrm{~mm}(=3 \mathrm{Fr})$ to insert the glass fiber, and another (diameter $0.8 \mathrm{~mm}$ ) for continuous flushing with contrast media or saline solution during the laser-induced lithotripsy (Figure 1). After insertion of the glass fiber, bending is possible up to about 90 degrees (Figure 2). In unfavorable situations (e.g. maximal flexion of the Alberan device), 45 degrees of flexion are still possible. It is only possible to bend the catheter tip in one direction. However, if the device is turned in the duodenoscope channel, it can be used in other directions as well.

Our initial experiences with the prototype catheter have shown promising results. The prototype catheter was successfully used for blind laser lithotripsy in some patients with retained bile duct stones that could not be properly targeted using standard endoscopic retrograd cholangiography catheters. The prototype catheter allowed correct fiber positioning in all of these cases. Some modification to the catheter (e.g. adding a balloon near the fiber tip) are in progress, and should help to reduce the need for choledochoscopy in laser lithotripsy.

A second series of catheters has also been developed with an outer diameter of $5 \mathrm{Fr}$ and a common channel (diameter $3 \mathrm{Fr}$ ) for flushing and for the glass fiber. The main use of this catheter will be to facilitate blind laser lithotripsy of pancreatic duct stones (5). Experience with this device has not yet been gathered. The catheter may help to establish a laser system for the treatment of pancreatic duct stones.

\section{R. Jakobs, J. F. Riemamn}

Dept. of Medicine C (Gastroenterology and Hepatology),

Municipal Hospital, Ludwigshafen, Germany

\section{Acknowledgment}

Dr. Jakobs's work was sponsored by the Ludwig Demling Grant, Europa-Stiftung Wissenschaft fürs Leben. Olympus Optical Co. Europe, Hamburg.

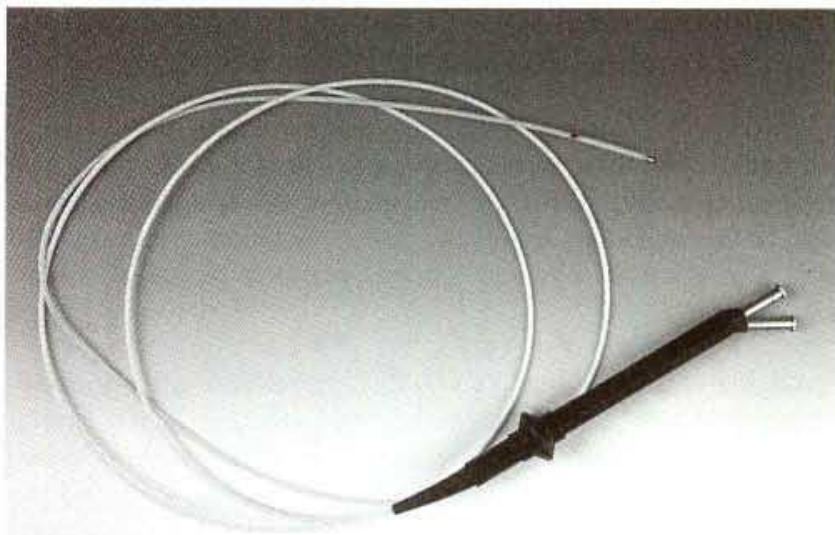

Figure 1: Appearance of the complete catheter

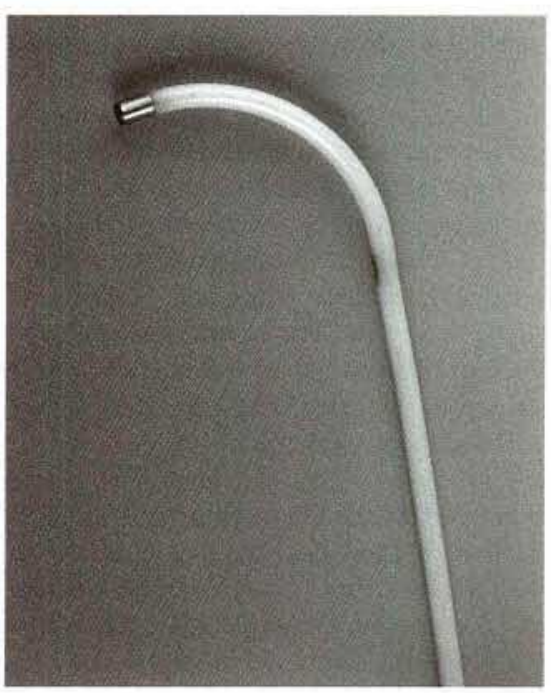

Figure 2: Catheter tip bent in one direction.

\section{References}

1. Ell C, Wondrazek F, Frank F, Hochberger J, Lux G, Demling L. Laser-induced shock-wave lithotripsy of gallstones. Endoscopy 1986; 18: 95-6.

2. Cotton PB, Kozarek RA. Schapiro RH, et al. Endoscopic laser lithotripsy of large bile duct stones. Gastroenterology 1990; 99: $1128-33$

3. Ell C, Hochberger J, May A, et al. Laser lithotripsy of difficult bile duct stones by means of a rhodamine- $6 \mathrm{G}$ laser and an integrated automatic stone-tissue detection system. Gastrointest Endosc 1993; 39: 755-62.

4. Jakobs R, Maier M, Kohler B, Rieman JF. Laser lithotripsy of difficult bile duct stones: does a stone-tissue discriminationsystem reduce the need for cholangioscopy? Gastroenterology 1995; 108: A418.

5. Jakobs R, Maier M, Kohler B, Riemann JF. Laser lithotripsy of pancreatic stones: in-vitro studies and first clinical results. Gastrointest Endosc 1994; 40: 380 (A).

Corresponding Author

R. Jakobs, M.D., Dept. of Medicine C (Gastroenterology and Hepatology), Municipal Hospital, Bremserstrasse 79, 67063 Ludwigshafen, Germany, Fax: +49-621-503-4114 